Original Article

\title{
Correlation of stress and muscle activity of patients with different degrees of temporomandibular disorder
}

\author{
Juliana de Paiva Tosato ${ }^{1)^{*}}$, Paulo Henrique Ferreira Caria, PhD²), \\ Cid Andre Fidelis de Paula Gomes ${ }^{3)}$, Fausto Berzin ${ }^{2}$, , Fabiano Politti ${ }^{1)}$, \\ Tabajara de Oliveira Gonzalez ${ }^{3}$, Daniela Aparecida Biasotto-Gonzalez ${ }^{1)}$ \\ 1) Department of Rehabilitation Sciences, University Nove de Julho: Aruja SP 07400-000, Brazil \\ 2) Department of Morphology, Piracicaba Dental School, State University of Campinas, Brazil \\ 3) Department of Physical Therapy, University Nove de Juho, Brazil
}

\begin{abstract}
Purpose] Temporomandibular disorder is one of the many different adverse health conditions that can be triggered by stress. Therefore, a biopsychosocial model has been proposed to characterize the multifactorial nature of temporomandibular disorder. The aim of the present study was investigate the correlation of salivary cortisol levels with the activities of the masseter and anterior temporal muscles of patients with different degrees of temporomandibular disorder. [Subjects and Methods] Forty-nine women between 18 and 40 years of age with a diagnosis of myogenous temporomandibular disorder based on the Research Diagnostic Criteria for temporomandibular disorders were evaluated using the Fonseca Index to determine the degree of the disorder. Salivary cortisol levels were determined and surface electromyography was used to evaluate electrical activity in the masticatory muscles. [Results] Positive correlations were found among the degree of temporomandibular disorder, electromyographic activity and salivary cortisol: as women with more severe temporomandibular disorder had greater electrical activity in the muscles analyzed, especially the anterior temporal muscle, and higher levels of cortisol. [Conclusion] Muscle activity was greater among individuals with severe temporomandibular disorder and positive correlations were found among electromyographic activity, salivary cortisol and the degree of temporomandibular disorder severity. Key words: Temporomandibular joint disorders, Electromyography, Cortisol
\end{abstract}

(This article was submitted Oct. 27, 2014, and was accepted Dec. 25, 2014)

\section{INTRODUCTION}

The way the human organism responds to stress can be positive, such as fast decisions and reactions when facing potential danger (fight or flight) ${ }^{1,2)}$. However, intense, long-lasting stress can have adverse health effects ${ }^{3)}$. Cortisol is released during a stressful event. This hormone is an essential corticosteroid which is involved in the restoration of homeostasis, ${ }^{4)}$ but it can be harmful when the organism is exposed to frequent stress. Humans responsed to stress results by an increasing expression of adrenocorticotropic hormone $(\mathrm{ACTH})$ and cortisol $^{5)}$.

Temporomandibular disorder (TMD) can be triggered by stress and is characterized by a variety of symptoms involving the masticatory muscles, temporomandibular joint and adjacent structures ${ }^{6,7)}$. The Research Diagnostic Criteria for Temporomandibular Disorders (RDC/TMD) is considered

\section{*Corresponding author. Juliana de Paiva Tosato (E-mail:} jptfisioterapia@ig.com.br)

C2015 The Society of Physical Therapy Science. Published by IPEC Inc. This is an open-access article distributed under the terms of the Creative Commons Attribution Non-Commercial No Derivatives (by-ncnd) License $<$ http://creativecommons.org/licenses/by-nc-nd/3.0/> the most complete assessment tool for the classification of TMD (muscle disorder, joint disc alteration, arthralgia, arthritis and osteoarthrosis $)^{8}$. Myogenous TMD is the most frequent type and is commonly caused by an increase in muscle activity triggered by emotional stress ${ }^{9,10)}$.

A number of tools are available for the evaluation of TMD, such as electromyography $(\mathrm{EMG})^{11)}$, since as individuals with this disorder exhibit hyperactivity of the masticatory muscles ${ }^{12)}$. Moreover, several authors have proposed a biopsychosocial model for the characterization of the multifactorial nature of TMD based on the close relationship between physical alterations and emotional wellbeing ${ }^{13,14)}$.

Andrade et al. ${ }^{15)}$ evaluated salivary cortisol in young adults with TMD, diagnosed using the RDC/TMD, and found the young adults had significantly higher levels in comparison to a control group. They concluded that cortisol evaluation can be used to complement the diagnosis of TMD, since there was demonstrating an association between cortisol and psychological factors. However, Jasim et al. ${ }^{16)}$ measured salivary cortisol in individuals with a diagnosis of orofacial pain and found they showed no difference from relation to asymptomatic individuals. These findings suggest that the relationship between pain and adrenocortical activity is complex and merits further investigation using specific diagnostic tools. 
To test on the hypothesis of positive correlations among TMD severity, EMG activity of the masticatory muscles and cortisol level, the aim of the present study was investigated the correlation of salivary cortisol levels with the activities of the masseter and anterior temporal muscles of patients with different degrees of TMD.

\section{SUBJECTS AND METHODS}

A cross-sectional study was conducted after receiving approval from the Human Research Ethics Committee of the Piracicaba School of Dentistry, State University of Campinas (Brazil) under process number 120/2008. Recruitment was performed through flyers distributed around the university campus soliciting the participation of women with TMD. The individuals who expressed interest answered a questionnaire with close-ended responses and were a briefly evaluated for conformity with the administered for the determination of women who met the eligibility criteria. The inclusion criteria were: the female gender, age between 18 and 40 years, a diagnosis of myogenous TMD based on the RDC/TMD, Angle Class I occlusion, and body mass index between 18 and $25 \mathrm{~kg} / \mathrm{m}^{2}$. The exclusion criteria were currently undergoing physiotherapeutic, dental or medicinal (analgesic, anti-inflammatory agent, muscle relaxant or vasoactive drug) treatment, oral lesions, preexisting disease, missing teeth, a history of facial trauma, mouth breathing and current smoking habit. Fifty-one of the 200 women screened met the eligibility criteria and were selected for the study. However, two volunteers were excluded due to blood contamination in the saliva samples used for the determination of cortisol level. Thus, the final sample was made up of 49 females.

The RDC/TMD allows the classification of individuals with TMD into three groups: I) muscle disorder; II) joint displacement; and III) other joint conditions ${ }^{8)}$. The measure has two axes. Axis I is used for the clinical examination, which is performed by a single examiner and allows the evaluation of muscle and joint pain, mouth opening pattern, mandibular range of motion, joint sounds and pain sensitivity during mandibular movements or palpation of the temporomandibular joint and masticatory muscles. Axis I takes approximately 20 minutes to administer.

The Fonseca Patient History Index was used to diagnose the severity of TMD and is an adequately valid, reliable method for identifying individuals with TMD that has been widely used in recent studies ${ }^{17-19}$ ). This Portuguese-language measure has 10 items, each with three response options: "yes" (scored as 10 points), "sometimes" (5 points) and "no" (0 points). The sum of the points for all items gives the overall score which is classified as follow: absence of TMD ( 0 to 15 points), mild TMD (20 to 45 points), moderate TMD (50 to 65 points) and severe TMD (70 to 100 points) ${ }^{17)}$.

Saliva was collected between 8 and 9 a.m. for the determination of cortisol, since the time of the day exerts and influences on the concentration of the hormone. The volunteers were instructed not to brush or floss their teeth two hours before the exam to avoid gingival bleeding, which would contaminate the sample, not to eat or drink anything one hour before the exam, to remain at rest 30 minutes be- fore the exam, and to rinse their mouths with water and mild gargling ten minutes before the exam. During the collection of saliva, the volunteers remained seated and were instructed to remove the cap from the salivett tube and place the cotton pad under the tongue for two to three minutes ${ }^{20}$. The cotton was then placed back into the tube and the cap was put on again. The samples were frozen, placed in a proper receptacle in a polystyrene cooler with recyclable ice and sent to the laboratory for analysis ${ }^{21,22)}$. The quantification of salivary cortisol is a reliable index of free cortisol in the plasma $^{23,24)}$. Saliva samples are obtained using a simple, non-invasive, stress-free method that is easily performed by untrained individuals ${ }^{25)}$.

Surface EMG was used for the evaluation of the electrical activities of the masticatory muscles. For this, a portable, battery-powered, eight-channel signal conditioning module (EMG System do Brasil) was used with a bandpass filter (frequency: 20 to $500 \mathrm{~Hz}$ ), an amplifier with a gain of 1,000 $\mathrm{x}$, and common-mode rejection ratio $>120 \mathrm{~dB}$, a 12-byte analog-digital converter, and active surface electrodes with a pre-amplified gain of $20 \times$. Following cleaning of the sites with cotton soaked in $70 \%$ alcohol ${ }^{26)}$, self-adhesive, disposable surface electrodes were attached over the masseter and anterior temporal muscles bilaterally, with placement guided by the point of greatest volume during contraction and the direction of the muscle fibers identification of these points. For such, the volunteers were instructed to clench the teeth and palpation of the muscles was performed.

The signal was captured during non-habitual chewing (isotonic contraction) for 10 seconds, maximum voluntary clenching (isometric contraction) for five seconds, and with the mandible in the physiologic rest position for 10 seconds.

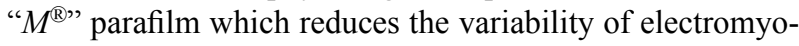
graphic readings was placed between the premolars and molars ${ }^{27}$. Each contraction condition was performed three times with a three-minute rest period between readings. The volunteers remained seated in a wooden chair with the back supported by the back of the chair, Frankfurt parallel to the floor, eyes open, their arms supported on the thighs, and their feet parallel and in contact with the floor.

A sliding window was used to scan the EMG signals and the mean of the three readings was used for the calculation of the root mean square (RMS) values, which were used in the data analysis. The data were normalized to the peak of the EMG signal, which had the lowest standard deviation. For the evaluation of the right and left masseter (RM and LM) and anterior temporal muscles (RT and LT), the following activity index was used: [(RM+LM-RT-LT)/ $(\mathrm{RM}+\mathrm{LM}+\mathrm{RT}+\mathrm{LT}) \times 100]^{28)}$. The results of this equation allow identifying the muscles that are predominant during than proposed activity. Negative values indicate greater activity of the temporal muscles, positive values indicate greater activity of the masseter muscles and a value of 0 indicates balance among the muscles.

Spearman's correlation coefficients (r) was calculated to determine the strength of correlations among the variables, and values of " $r$ " were interpreted as follows: $0=$ no correlation; 0 to $0.3=$ weak correlation; 0.31 to $0.6=$ moderate correlation; 0.61 to $0.9=$ strong correlation; 0.91 to $0.99=$ very strong correlation; and $1=$ complete correlation. The 
Table 1. Spearman's correlation coefficients for the electromyographic activities of the in masticatory muscles and the degree of TMD severity

\begin{tabular}{lccccccccccccc}
\hline & \multicolumn{4}{c}{ Rest } & \multicolumn{4}{c}{ Isotonic contraction } & \multicolumn{4}{c}{ Isometric contraction } \\
\hline & LM & LT & RM & \multicolumn{1}{c}{ RT } & LM & LT & RM & RT & LM & LT & \multicolumn{1}{c}{ RM } & RT \\
\hline Mild & 0.36 & -0.5 & 0.46 & -0.44 & 0.07 & 0.21 & 0.01 & -0.01 & 0.01 & 0.13 & -0.08 & -0.05 \\
Moderate & 0.23 & 0.18 & 0.15 & -0.36 & 0.03 & 0.06 & 0.04 & 0.01 & 0.11 & -0.37 & -0.08 & 0.04 \\
Severe & 0.7 & 0.54 & 0.65 & 0.21 & 0.43 & $0.81^{*}$ & 0.05 & $0.81^{*}$ & 0.32 & 0.65 & 0.32 & $0.76^{*}$ \\
\hline
\end{tabular}

*Statistically significant difference $\mathrm{p}<0.05$

Table 2. Spearman's correlation coefficients for the electromyographic activities of the masticatory muscles and salivary cortisol according to degree of TMD severity

\begin{tabular}{lrrrrrrrrrrrrr}
\hline & \multicolumn{4}{c}{ Rest } & \multicolumn{4}{c}{ Isotonic contraction } & \multicolumn{4}{c}{ Isometric contraction } \\
\hline & LM & \multicolumn{1}{c}{ LT } & \multicolumn{1}{c}{ RM } & \multicolumn{1}{c}{ RT } & \multicolumn{1}{c}{ LM } & \multicolumn{1}{c}{ LT } & \multicolumn{1}{c}{ RM } & RT & LM & \multicolumn{1}{c}{ LT } & RM & RT \\
\hline Mild & -0.36 & -0.37 & -0.13 & -0.34 & -0.18 & -0.30 & -0.14 & -0.26 & -0.17 & -0.14 & -0.18 & -0.35 \\
Moderate & -0.01 & -0.07 & 0.33 & -0.03 & 0.25 & 0.33 & 0.15 & 0.18 & 0.09 & 0.08 & 0.14 & 0.24 \\
Severe & 0.67 & 0.57 & 0.17 & 0.03 & 0.35 & 0.61 & 0.42 & 0.61 & $0.71^{*}$ & 0.67 & $0.64^{*}$ & 0.46 \\
\hline
\end{tabular}

*Statistically significant difference $\mathrm{p}<0.05$

Table 3. Median and interquartile interval ( 25 and $75 \%)$ of cortisol according to three degrees of TMD severity determined using the Fonseca Index ( $p<0.008$, KruskalWallis test; $* \mathrm{p}<0.05$; Dunn's post hoc test)

\begin{tabular}{lccc}
\hline & Mild & Moderate & Severe \\
\hline Cortisol $(\mu \mathrm{g} / \mathrm{dl})$ & $25.39(16.28-75.07)$ & $116.7(47.75-191.3) *$ & $250.1(35.05-317.7) *$ \\
\hline *Statistically significant difference $\mathrm{p}<0.05$ & &
\end{tabular}

Kruskal-Wallis test was employed to determine whether the activity index differed among the different degrees of TMD severity. The level of significance was chosen as $5 \%(\mathrm{p}<$ 0.05). All data analyses and processing were performed with the aid of the BioEstat program, version 5.3 (Belém, PA, Brazil).

\section{RESULTS}

Table 1 displays the correlation coefficients for degree of TMD severity and EMG activity under the different contraction analyzed. Moderate to strong correlations were found between severe TMD and EMG activity for all of the contraction. The strongest correlations were observed in the group of women with severe TMD regarded the temporal muscles during isotonic and isometric contractions of the temporal muscle.

Moderate to strong correlations were found between salivary cortisol and EMG activities of the women with severe TMD (Table 2).

Table 3 shows the correlation between cortisol and TMD severity. The correlation was positive and strongest ( $\mathrm{r}=$ 0.70 ) for subjects with the hormone and severe TMD.

The activity index results show that the data on the activity index, during non-habitual chewing (isotonic contraction), the activity of the anterior temporal muscles was predominantly independently of the degree of TMD severity. During maximum voluntary clenching (isometric contraction), activity in the masseter muscles was predomi- nant in the groups with mild and severe TMD, and slightly predominant in the group with moderate TMD. However, no statistically significant differences were found among the different degrees of TMD (mild, moderate and severe) ( $p>$ 0.05, Kruskal-Wallis test).

\section{DISCUSSION}

Pinheiro et al. ${ }^{29)}$ suggested that gender and age differences exert an influence on the occurrence of TMD. To minimize these influences, only women aged 20 to 40 years were recruited for the present study, as TMD is more prevalent in this gender and age range ${ }^{30}$ ).

Although it was despite methodological differences, the study most similar to the present investigation was conducted by Ardizone et al. ${ }^{11)}$, who evaluated EMG patterns in patients with different degrees of TMD severity, but using the Helkimo Index rather than the Fonseca Index, and found lower muscle activity in the group with severe TMD during maximum voluntary contraction. In contrast, muscle activity was greatest among the women with severe TMD in the present investigation. This difference in these results may be attributable to the data collection time, since Ardizone et al. cited evaluated maximum contraction for 15 seconds, which may have caused pain during the reading and consequently lower muscle contraction potential. The occurrence of hyperactive muscles in the present investigation is in agreement with the study of Bodéré et al., who also reported an increase in activity of the masseter and temporal muscles of 
individuals with $\mathrm{TMD}^{31)}$.

The activity index demonstrated the predominance of activation of the temporal muscles over the masseter muscles. Takemura et al., reported that bruxism is one of the main triggering factors of myogenous TMD, which is characterized by constant involuntary contractions that can lead to a reduction in the ability of the masseter muscle to generate force ${ }^{32}$. Thus, the temporal muscles assume on additional functions to compensate for the loss of masseter muscle strength, positioning the head of the mandible in the mandibular fossa (its main function) and generating force during mandible elevation movements ${ }^{33}$. According to Nielsen et al. ${ }^{34)}$, the inversion of the activity of the temporal and masseter muscles during chewing is a compensatory mechanism for minimizing pain in a motor response in individuals with TMD, which is believed to be an adaptation by the elevator muscles of the mandible following the onset of $\mathrm{TMD}^{35)}$.

According to Lipp and Novaes ${ }^{36}$, stress plays an important triggering role in various adverse health conditions, but is often not the causal factor, as an individual must have a predisposition to the condition in question. The higher cortisol levels among women with more severe TMD indicates that stress may have triggered more symptoms and at a greater frequency, as demonstrated by the Fonseca Index. The amount of circulating cortisol varies throughout the day, with higher levels in the morning and lower levels at night ${ }^{37}$. Moreover, changes in the cortisol secretion patterns are associated with depression, psychological stress, trauma, fear, pain and physical exercise. Castro and Moreira ${ }^{5}$ described the influence of physical and emotional stress on the secretion of ACTH, concluding that the response to stress affects feedback mechanisms and the circadian rhythm, which resulting in an increase in both ACTH and cortisol.

Jones et al. ${ }^{38)}$ investigated the correlation of salivary cortisol with TMD in 36 women and found that the women group proved to be heterogeneous, as part of the group exhibited hypersecretion of the hormone, while no difference was found between the remaining volunteers and the control group. Thus, their findings were inconclusive. In contrast, a moderate correlation was found between cortisol level and TMD severity in the present investigation $(r=$ 0.467). Korszun et al. ${ }^{39)}$ measured the cortisol level in the blood of 15 women with TMD, and 15 controls and found an increase in the cortisol level of the group with TMD, which is in agreement with the present findings. The authors cited concluded that irregularity in the production of the cortisol hormone may be caused by the perception of facial pain, and may in turn stimulate pain throughout the entire body. Individuals with TMD exhibit pain characteristics that may activate the sympathetic nervous system and the hypothalamus-pituitary-supradrenal axis, which regulates the reactions to stress.

It should be pointed out that psychological factors may trigger physical symptoms, such as muscle tension, which may result from a poorly adapted response to psychological stress ${ }^{40)}$. According to Borini et al. ${ }^{41)}$, anxiety can exert an influence on EMG readings of the masseter and anterior temporal muscles in healthy individuals. Moreover, Bakker et al. ${ }^{42)}$ state that the temporal muscle is more susceptible to emotional stress than the masseter muscle. Tsai et al. ${ }^{43)}$ con- ducted an experiment in which EMG activity of the masticatory muscles was increased significantly under a condition of induced stress. While induced stress was not employed in the present investigation, muscle activity increased proportionally with the increase of cortisol. Ruf et al. ${ }^{44)}$ report similar findings in a study addressing the effect of non-experimental stress on the function of the masseter and temporal muscles in young adults without TMD. Experimental studies have demonstrated that stress factors can increase EMG activity ${ }^{45}$, 46), leading to the hypothesis that the change in muscle pattern is a powerful triggering factor of orofacial disorders, which may explain the correlation found for the volunteers analyzed in the present study. Rissén et al. ${ }^{46)}$ also report that emotions tend to provoke different physiological responses, as demonstrated by the greater EMG activity in the upper portion of the trapezius muscle associated with negative stress at a supermarket check-out.

The present findings demonstrate interactivity among emotional and physical variables. The increase in cortisol, which is a hormone released in situations of stress, was concomitant with to greater muscle activity and TMD severity. Further studies with a larger number of volunteers should be conducted to allow a better definition of this relationship in order to support to the treatment of individuals with TMD.

\section{ACKNOWLEDGEMENT}

This research was funded by the Brazilian Council for the Improvement of Higher Education Personnel (CAPES).

\section{REFERENCES}

1) Nahas MV: Atividade Física, Saúde e Qualidade de Vida: Conceitos e sugestões para um estilo de vida ativo, 4th ed. Londrina: Midiograf, 2006.

2) Taylor SE, Klein LC, Lewis BP, et al.: Biobehavioral responses to stress in females: tend-and-befriend, not fight-or-flight. Psychol Rev, 2000, 107: 411-429. [Medline] [CrossRef]

3) Niemman D: Exercício e Saúde, 1st ed. São Paulo: Manole, 1999.

4) Shin IY, Ahn RS, Chun SI, et al.: Cortisol awakening response and nighttime salivary cortisol levels in healthy working Korean subjects. Yonsei Med J, 2011, 52: 435-444. [Medline] [CrossRef]

5) Castro M, Moreira AC: Análise crítica do cortisol salivar na avaliação do eixo hipotálamo-hipófise-adrenal. Arquivos brasileiros de endocrinologia metabólica 2003, 47: 358-367.

6) Lauriti L, Silva PF, Politti F, et al.: Pattern of electromyographic activity in mastication muscles of adolescents with temporomandibular disorder. $\mathrm{J}$ Phys Ther Sci, 2013, 25: 1303-1307. [Medline] [CrossRef]

7) Lauriti L, Motta LJ, Silva PF, et al.: Are occlusal characteristics, headache, parafunctional habits and clicking sounds associated with the signs and symptoms of temporomandibular disorder in adolescents? J Phys Ther Sci, 2013, 25: 1331-1334. [Medline] [CrossRef]

8) Dworkin SF, LeResche L: Research diagnostic criteria for temporomandibular disorders: review, criteria, examinations and specifications, critique. J Craniomandib Disord, 1992, 6: 301-355. [Medline]

9) Kashima K, Igawa K, Maeda S, et al.: Analysis of muscle hardness in patients with masticatory myofascial pain. J Oral Maxillofac Surg, 2006, 64: 175-179. [Medline] [CrossRef]

10) Motamedi MH: An assessment of maxillofacial fractures: a 5-year study of 237 patients. J Oral Maxillofac Surg, 2003, 61: 61-64. [Medline] [CrossRef]

11) Ardizone I, Celemin A, Aneiros F, et al.: Electromyographic study of activity of the masseter and anterior temporalis muscles in patients with temporomandibular joint (TMJ) dysfunction: comparison with the clinical dysfunction index. Med Oral Patol Oral Cir Bucal, 2010, 15: e14-e19. [Medline]

12) Roark AL, Glaros AG, O'Mahony AM: Effects of interocclusal appliances on EMG activity during parafunctional tooth contact. J Oral Rehabil, 
2003, 30: 573-577. [Medline] [CrossRef]

13) Inoue-Minakuchi M, Maekawa K, Kuboki T, et al.: Intramuscular haemodynamic responses to different durations of sustained extension in norma human masseter. Arch Oral Biol, 2001, 46: 661-666. [Medline] [CrossRef]

14) Rudy TE, Turk DC, Kubinski JA, et al.: Differential treatment responses of TMD patients as a function of psychological characteristics. Pain, 1995 , 61: 103-112. [Medline] [CrossRef]

15) Da Silva Andrade A, Gamero GH, Pereira LJ, et al.: Salivary cortisol levels in young adults with temporomandibular disorders. Minerva Stomatol, 2008, 57: 109-116. [Medline]

16) Jasim H, Louca S, Christidis N, et al.: Salivary cortisol and psychological factors in women with chronic and acute oro-facial pain. J Oral Rehabil, 2014, 41: 122-132. [Medline] [CrossRef]

17) Gomes CA, Dibai-Filho AV, Silva JR, et al.: Correlation between severity of temporomandibular disorder and mandibular range of motion. J Bodyw Mov Ther, 2014, 18: 306-310. [Medline] [CrossRef]

18) Gomes CA, Politti F, Andrade DV, et al.: Effects of massage therapy and occlusal splint therapy on mandibular range of motion in individuals with temporomandibular disorder: a randomized clinical trial. J Manipulative Physiol Ther, 2014, 37: 164-169 [CrossRef]. [Medline]

19) Campos JA, Gonçalves DA, Camparis CM, et al.: Reliability of a questionnaire for diagnosing the severity of temporomandibular disorder. Rev Bras Fisioter, 2009, 13: 38-43. [CrossRef]

20) Kai S, Koga M: Autonomic nerve responses in a psychological stres task and subsequent slow breathing. J Phys Ther Sci, 2012, 24: 257-259. [CrossRef]

21) Raff H: Salivary cortisol: a useful measurement in the diagnosis of Cushing's syndrome and the evaluation of the Hypothalamic Pituitary-Adrenal Axis. Endocrinologist, 2000, 10: 9-17. [CrossRef]

22) Papanicolaou DA, Mullen N, Kyrou I, et al.: Nighttime salivary cortisol: a useful test for the diagnosis of Cushing's syndrome. J Clin Endocrinol Metab, 2002, 87: 4515-4521. [Medline] [CrossRef]

23) Walker RF, Riad-Fahmy D, Read GF: Adrenal status assessed by direct radioimmunoassay of cortisol in whole saliva or parotid saliva. Clin Chem, 1978, 24: 1460-1463. [Medline]

24) Umeda T, Hiramatsu R, Iwaoka $T$, et al.: Use of saliva for monitoring unbound free cortisol levels in serum. Clin Chim Acta, 1981, 110: 245-253. [Medline] [CrossRef]

25) Antonini SR, Jorge SM, Moreira AC: The emergence of salivary cortisol circadian rhythm and its relationship to sleep activity in preterm infants. Clin Endocrinol (Oxf), 2000, 52: 423-426. [Medline] [CrossRef]

26) Ding R, Logemann JA, Larson CR, et al.: The effects of taste and consistency on swallow physiology in younger and older healthy individuals: a surface electromyographic study. J Speech Lang Hear Res, 2003, 46 977-989. [Medline] [CrossRef]

27) Ap Biasotto-Gonzalez D, Berzin F, da Costa JM, et al.: Electromyographic study of stomatognathic system muscles during chewing of different materials. Electromyogr Clin Neurophysiol, 2010, 50: 121-127. [Medline]

28) Naeije M, McCarroll RS, Weijs WA: Electromyographic activity of the human masticatory muscles during submaximal clenching in the inter-cuspal position. J Oral Rehabil, 1989, 16: 63-70. [Medline] [CrossRef]

29) Pinheiro RS, Viacava F, Travassos C, et al.: Gênero, morbidade, acesso e utilização de serviços de saúde no Brasil. Cien Saude Colet, 2002, 7 : 687-707. [CrossRef]

30) Alamoudi N, Farsi N, Salako NO, et al.: Temporomandibular disorders among school children. J Clin Pediatr Dent, 1998, 22: 323-328. [Medline]

31) Bodéré C, Téa SH, Giroux-Metges MA, et al.: Activity of masticatory muscles in subjects with different orofacial pain conditions. Pain, 2005, 116: 33-41. [Medline] [CrossRef]

32) Takemura T, Takahashi T, Fukuda M, et al.: A psychological study on patients with masticatory muscle disorder and sleep bruxism. Cranio, 2006, 24: 191-196. [Medline] [CrossRef]

33) Caria PH, Bigaton DR, de Oliveira AS, et al.: Fatigue analysis in the masseters and temporalis muscles in patients with temporomandibular disorder during short period of mastication. Acta Odontol Latinoam, 2009, 22: 87-91. [Medline]

34) Nielsen IL, McNeill C, Danzig W, et al.: Adaptation of craniofacial muscles in subjects with craniomandibular disorders. Am J Orthod Dentofacial Orthop, 1990, 97: 20-34. [Medline] [CrossRef]

35) Sato S, Kawamura H: Natural course of non-reducing disc displacement of the temporomandibular joint: changes in electromyographic activity during chewing movement. J Oral Rehabil, 2005, 32: 159-165. [Medline] [CrossRef]

36) Lipp MN, Novaes LE: Mitos \& Verdades sobre o Stress. São Paulo: Ed. Contexto, 1996.

37) Kim K, Park S, Goo BO, et al.: Effect of self-myofascial release on reduction of physical stress: a pilot study. J Phys Ther Sci, 2014, 26: 1779-1781. [Medline] [CrossRef]

38) Jones DA, Rollman GB, Brooke RI: The cortisol response to psychological stress in temporomandibular dysfunction. Pain, 1997, 72: 171-182. [Medline] [CrossRef]

39) Korszun A, Young EA, Singer K, et al.: Basal circadian cortisol secretion in women with temporomandibular disorders. J Dent Res, 2002, 81: 279-283. [Medline] [CrossRef]

40) Crofford LJ, Casey KL: Central modulation of pain perception. Rheum Dis Clin North Am, 1999, 25: 1-13. [Medline] [CrossRef]

41) Borini CB, Duarte CL, Amorim MM, et al.: Análise da influencia da ansiedade sobre o sinal eletromiográfico. RGO -. Rev Gaucha Odontol, 2010, 58: 225-230.

42) Bakke M, Tuxen A, Thomsen CE, et al.: Salivary cortisol level, salivary flow rate, and masticatory muscle activity in response to acute mental stress: a comparison between aged and young women. Gerontology, 2004, 50: 383-392. [Medline] [CrossRef]

43) Tsai CM, Chou SL, Gale EN, et al.: Human masticatory muscle activity and jaw position under experimental stress. J Oral Rehabil, 2002, 29: 4451. [Medline] [CrossRef]

44) Ruf S, Cecere F, Kupfer J, et al.: Stress-induced changes in the functional electromyographic activity of the masticatory muscles. Acta Odontol Scand, 1997, 55: 44-48. [Medline] [CrossRef]

45) Lassauzay C, Peyron MA, Albuisson E, et al.: Variability of the masticatory process during chewing of elastic model foods. Eur J Oral Sci, 2000, 108: 484-492. [Medline] [CrossRef]

46) Rissén D, Melin B, Sandsjö L, et al.: Surface EMG and psychophysiological stress reactions in women during repetitive work. Eur J Appl Physiol, 2000, 83: 215-222. [Medline] [CrossRef] 